\title{
Using Debate in an Online Asynchronous Social Policy Course
}

\author{
Elissa Thomann Mitchell \\ University of Southern Indiana
}

\begin{abstract}
This paper presents the use of a debate in an online asynchronous social policy course. Debate is frequently used as an instructional strategy in higher education, but little is known about the use of this tool in an online learning environment. Participants $(N=36)$ completed an online debate assignment, and both qualitative (reflection papers) and quantitative (survey) data were gathered to learn about the effectiveness of the assignment, and what students learned, liked, and disliked about the project. A majority of students reported the debate assignment helped them further understand course concepts, understand concepts better than lecture or reading would have, use or improve critical thinking skills, and improve collaboration among students in the course. Key themes from qualitative data are also reported, as well as recommendations for using this assignment in other courses.
\end{abstract}

Keywords: asynchronous, online debate, teaching social policy

Mitchel, E.T. (2019). Using debate in an online asynchronous social policy course. Online Learning, 23(3), 21-33. doi:10.24059/olj.v23i3.2050

\section{Acknowledgement}

This work began when the author was an Assistant Professor and Faculty Fellow for the Center for Online Learning, Research, and Service at the University of Illinois Springfield.

\section{Using Debate in an Online Asynchronous Social Policy Course}

The purpose of this paper is to describe how a debate assignment was used in an online asynchronous social policy course, and to reflect on student feedback and learning from this assignment. Social policy courses cover sometimes sensitive topics about which students may have conflicting viewpoints. One of the ways to address this issue and to depersonalize some of the topics is to structure a debate where students must argue from a certain perspective. Debate is a common instructional technique used in many disciplines, particularly the social sciences, and has been linked to the development of critical thinking skills (Freeley, 1996). The effectiveness of debate as a course assignment has been assessed in different disciplines and from varied 
perspectives, including the development of critical thinking skills, improving student research and writing skills, and overall student engagement (Budesheim \& Lundquist, 1999; Kennedy, 2009; Omelicheva \& Avdeyeva, 2008). Less is known, however, about using debate in an online asynchronous environment (Park, Kier, \& Jugdev, 2011). One of the challenges of online instruction can be moving activities from the traditional seated classroom to an online platform and achieving the same learning outcomes (Bates \& Watson, 2008). This descriptive study explores the implementation of a debate assignment in an asynchronous online policy course, reports on student feedback related to this assignment, and provides recommendations for other faculty wishing to adopt a similar assignment.

\section{Review of Literature}

\section{Debate as an Instructional Tool}

Debate is a common instructional technique used in many different types of courses. It can be especially effective in courses where there is more than one "right" answer or perspective or when understanding differing viewpoints is important (e.g., in a social policy course). Instructors in several disciplines have used debate and examined its effectiveness in the classroom in encouraging active learning and critical thinking among students (Budesheim \& Lundquist, 1999; Kennedy, 2009) and enhancing the overall learning process and student engagement (Omelicheva \& Avdeyeva, 2008). However, there are limited studies related to using debate in a social policy course (Gregory \& Holloway, 2005).

Particularly relevant to this research, Keller, Whittaker, and Burke (2001) explored the use of debate in a policy course and found that the assignment improved student policy knowledge and skills related to policy practice. In fact, student participants reported the debate was more valuable to them in developing topical knowledge than other more traditional forms on instruction (Keller et al., 2001). Students reported that the debates helped them think about issues from a different perspective and to think more critically-important in policy analysis and practice. Likewise, Gregory and Holloway (2005) examined debate as an instructional strategy in a social policy course. They also found that debate helped students develop critical thinking and argumentation skills, essential to effective policy practice in social work. Both Keller and colleagues (2001) and Gregory and Holloway (2005) reported on some of the challenges associated with a classroom debate, such as logistics (e.g., time) and working in a group. These challenges are consistent with previous literature regarding debate as an instructional tool (Schroeder \& Ebert, 1983). While these challenges were taken into consideration in developing the debate assignment for this project, less is known about using debate in an online learning environment.

\section{Online Debate}

Online education is a growing field, with over $30 \%$ of college students taking at least one online course in 2016 (Seaman, Allen, \& Seaman, 2018). Many colleges and universities are exploring ways to expand or extend their programs to students online. Some programs are offering courses completely online, while others are using a blended approach, incorporating online components into their existing courses. One of the challenges, however, is adapting traditional methods of instruction to online course delivery modes (Bates \& Watson, 2008). Researchers have argued that online courses can be "as effective as traditional instruction when the method and technologies used are appropriate to the instructional tasks, there is student-to-student interaction, 
and timely teacher-to-student feedback" (Hamzaee, 2005, p. 216). According to Clark (1994), the methods used in instruction - not the media - are most important in learning outcomes. It is therefore logical to think that, consistent with a debate in a face-to-face course, an online debate could be used to generate or increase participation from students and increase or improve critical thinking skills.

Richardson and Ice (2010) compared the effectiveness of three different types of online discussions (open-ended discussion, a debate, and a case-based discussion), in improving students' critical thinking skills. Using the Practical Inquiry Model (PIM; Garrison, Anderson, \& Archer, 2001), they found that debate improved students' critical thinking achievement levels more than a typical open-ended discussion but slightly less than a case-based discussion. In another study, Weeks' (2013) examined an online debate assignment in a graduate course on leadership and found that online students had higher levels of participation and performance (i.e., better work and higher grades) on the assignment compared to students in her traditional seated course. Weeks (2013) noted that students seemed to think more deeply before posting online versus discussing the topics in class. In reflecting on her experience, Weeks noted that online debates last longer, providing students the opportunity to examine the topic differently - and perhaps more deeply - than inperson discussions. She concluded that online debate can be effective in increasing engagement in course discussions and prompting more complex or deep thought about the issues (Weeks, 2013). Richardson and Ice (2010) also noted that extended time may be needed to allow students to more fully engage in the critical thinking process. Likewise, in their exploration of online debate's ability to spur critical thinking in students, Mutiaraningrum and Cahyono (2015) found that the deliberate planning of a debate (e.g., assigned roles, expectations) helped students post more thoughtful and critical arguments. Mutiaraningrum and Cahyono (2015) also noted the flexibility of online debate, allowing both students and the instructor time to engage with and reflect on the material.

Park, Kier, and Jugdev (2011) examined debate as a teaching strategy in online education from the perspective of three faculty members in different disciplines. While each instructor approached the debate differently, debated different topics, and integrated the assignment into their course in a different way, Park and colleagues suggest that debates can be used "regardless of the mode of delivery ... in paced or un-paced online courses ... [and] at both the undergraduate and graduate levels of education" (2011, p. 14). They recommended that future research examine faculty and student experiences and perceptions with debate as an instructional strategy.

\section{Purpose of This Research}

Given this recommendation and the limited body of research related to the implementation and effectiveness of online debate, the purpose of this study was to explore debate as an assignment in an online asynchronous course and to examine whether this was a viable instructional strategy for this course moving forward. Note that the debate assignment used in this course was not just a debate held in a week or two on a discussion board, but a formal semester-long assignment with students working in groups. This differentiates this assignment from previous work in this area. Research questions that were addressed include (1) whether students liked this type of assignment and (2) what students learned from the assignment, specifically whether the debate helped with critical thinking skills. Thus, this descriptive paper examines the implementation of an asynchronous online debate in an online policy course using both quantitative and qualitative data, as well as reflections and recommendations for using this assignment in other courses and considerations for future research. 


\section{Methods}

\section{Procedure}

Based on best practices in the existing literature regarding debate and online learning, an asynchronous online debate assignment was created and implemented in three sections of a policy course over an 18-month period. Distinct from some debate assignments discussed in the literature (e.g., Richardson \& Ice, 2010; Weeks, 2013), this assignment was not held solely on the discussion board. Students were required to write papers, work collaboratively with assigned groups, and respond in a written rebuttal as a group. The policy debate assignment has several components and deadlines; a detailed guide of each required piece of the project, the specifics of each assignment, and accompanying deadlines were provided to the class, and a summary of the components is provided in Table 1 for reference.

Table 1

\section{Debate Assignment Components}

$\begin{array}{ll}\text { Assignment component } & \text { Timeline } \\ \text { Individual position statement } & \text { Week 1 } \\ \text { Group position statement } & \text { Week 3 } \\ \text { Rebuttal } & \text { Week 6 } \\ \text { Open discussion forum } & \text { Week } 8 \\ \text { Reflection paper* } & \text { Week } 9 \\ \text { Peer Evaluation } & \text { Week } 9 \\ \text { Survey* } & 3-6 \text { months after course was complete }\end{array}$

Note. Only the Reflection paper and the Survey data were used in this paper.

The first component of the assignment was an individual position statement. Students were randomly assigned to either the pro or the con side of the debate topic (selected by the class) and required to research the topic and write a 2-3 page position statement representing their assigned perspective and citing the scholarly literature. This allowed students to familiarize themselves with the topic and the literature before working with one another to create the group position statement. The group position statement was a collaborative effort, and students had page and reference requirements to meet. The group position statements were posted on the course website; students then had to read the other side's position statement and work together to post a group rebuttal statement and further make their own case. The purpose of this was to give students more time to examine the issue and the other side's argument and then craft a thoughtful response, thus addressing the time issue mentioned by previous research (Richardson \& Ice, 2010; Weeks, 2013). At the end of this process, an online discussion forum was opened where students were asked to continue posting from their assigned perspective in an open debate; a minimum number of posts was required. Additional components of the assignment after the debate was complete included peer evaluation of the group members and a reflection paper on the project itself. After the course was complete, students were also asked to take an anonymous survey reporting on their experience with this assignment. While only the reflection paper and survey data were used in this paper, the assignment components and brief description are provided here for context and for those who may be interested in implementing a similar assignment in their own courses. 


\section{Participants}

Students enrolled in three different sections of an online policy course across three semesters (42 students total) were assigned to complete the online debate project. Consistent with university IRB protocol for course projects, students were given an informed consent form and notified of the existing research project once the course project was complete; they then agreed or disagreed with having their assignment participation and feedback used for the project. Only those students who signed and returned the consent form were included in this study $(N=36)$. All participants $(86 \%$ female) were graduate students enrolled in a hybrid human services program taking the social policy course in which this project was completed. All students had some exposure to and experience with online learning and asynchronous courses (i.e., had taken at least one online asynchronous class).

\section{Measures}

To address the questions about whether students liked the assignment and what they learned from it, measures included in the analysis for this descriptive project include a reflection paper at the end of the project and a survey sent after the course was complete.

Reflection paper. Qualitative data was gathered from students' reflection papers, where they were asked to comment on the debate assignment. Specifically, students were asked to write about what they liked, what they did not like, what they learned, and suggestions for improvements to the assignment. Reflection papers were submitted by students on the course learning management system. After the course was complete, the papers were downloaded, and identifying information was removed before analysis for this project.

Survey. The survey was conducted online, and students who agreed to participate were sent an anonymous link to respond; $100 \%$ of students who agreed to participate returned the survey. Survey questions were created by the author and were selected based on qualities important to the course, the assignment, and the relevant literature. Questions addressed understanding, engagement, critical thinking, and other key aspects of the assignment.

\section{Analysis}

Quantitative data from the survey was examined, and simple percentages of agreement and disagreement were calculated. The qualitative data in the reflection papers was coded for emerging themes or topics using qualitative techniques developed by Strauss and Corbin (2008). Open coding was used to generate a list of broad topics or categories discussed by the students. Thematic analysis was then used to analyze data based on these topics. The most common themes are reported here.

\section{Results}

\section{Quantitative Data}

Approximately 3-6 months after the course was completed, students received a survey asking about their experiences with the debate assignment. Table 2 displays the percentage of students that agreed or strongly agreed that the debate assignment helped in each area. A majority of students (a range of 78-92\%) agreed or strongly agreed that the debate assignment helped them further understand course concepts, understand concepts better than lecture or reading would have, helped them use or improve critical thinking skills, and improved collaboration among students in 
the course. Fifty-seven percent of students agreed or strongly agreed that the debate experience had helped in other courses or work, while only $28 \%$ of students reported that the debate project helped them feel more engaged in the course. See Table 2 for the percentage of participants who agreed (A) or strongly agreed (SA) with each statement.

Table 2

Percentage of Students That Strongly Agreed or Agreed With Each Statement

Strongly

Statement

1. The debate helped me further

understand course concepts.

2. The debate helped me feel more

engaged in the course.

3. The debate helped me understand

concepts from the course better than a

lecture or reading would have.

4. The debate helped me use and/or

improve my critical thinking skills.

5. The debate improved collaboration

among students in the course.

6. My experience with the debate has

helped me in other courses or in my work. agreed (SA)

13

15

18

50

50

7
Agreed (A)

67

13

60

42

42

50
Total SA/A

combined

80

28

78

92

92

57

\section{Qualitative Data}

The major themes that emerged from students' qualitative responses are presented below, along with student quotes to illustrate each theme.

Feeling apprehensive. One of the key themes that emerged was that students were apprehensive about engaging in a debate and doing so in a group, and they were especially nervous about completing this work in an online setting. One student commented, "I was nervous about doing a debate because I knew it would require a lot of research to back-up my argument." Another commented on the aggressive nature that can sometimes be present in debates: "I am generally a passive person and do not like to argue." Several students commented on the group aspect, especially for a semester-long project. One student remarked, "I was nervous about how I would work with a group without even meeting them in person." Another stated, "I have had negative experiences in group projects before and I am really uncomfortable with putting my grade in the hands of others." Lastly, a few students commented on the novelty of an online debate. For example, one student wrote, "I have never done a debate online and a little nervous about how this is going to go." Some students also commented that this apprehension seemed to affect their attitude toward the project initially. However, many of these fears were allayed once the project actually began and students were actively engaged with one another and the professor.

Challenged own viewpoint and opinions. Another common thread in the student comments was the fact that the debate forced students outside their comfort zones and made them examine their own views and opinions. Because students were randomly assigned to the pro or con stance, they were not always able to rely on their prior knowledge and views. One student wrote, "As I researched and wrote about [the debate topic] from a point of view that I have 
disagreed with, I found myself challenged to think differently. I found that the problem was that I was looking at the topic from only one perspective, my perspective, my beliefs, opinions, etc. I saw no other way around it or how to potentially argue for it." Another student reported having "a hard time with this debate because I am arguing for something that I don't believe." This forced students to rely on the literature and data to support their arguments, instead of emotion and opinion; this is a goal in policy practice. As one student said, this assignment "helped me understand why some individuals see the system the way they do. A change in perspective can open up your eyes to a whole lot of things that I did not see before."

Difficulty with group communication/group conflict. Because this was a group project, some students commented on the challenges they faced, such as communication, time management, and group conflict. One student wrote that "working with a team is challenging ... especially online. It's hard to do things when we aren't physically meeting with each other or seeing each other face to face." This was echoed by a couple students, but several students also reported how they managed this challenge in an online course. "My group used Skype to connect," one student wrote, and "I would suggest possibly making it a requirement that group members communicate via Skype. I enjoy face-to-face communication when working with others." Some students commented on the anxiety they felt being required to work in a group. For example, two students said, "It is difficult when working in a group since people have very different lives and work/school schedules," and "Group projects definitely cause some anxiety. I don't like to wait until the last minute to do things like some people." Others acknowledged this concern but found the project went better than expected: "Usually, I am not a big fan of group assignments because not everyone contributes, but they still get the same grade as the rest of the group. This was not the case with the debate assignment. I think that because the topic was so interesting, everyone wanted to do research and contribute to the assignment." Another student remarked, "I usually don't like to work in groups because it is difficult to find time to get together and count on each other, but this group worked well together to reach a common position." While group conflict was referenced a few times, there were no substantial issues during the assignment that came to the attention of the professor.

Gained knowledge. Students also frequently reported learning new content about the debate topic, perhaps more than they would have through other instructional methods. One student wrote, "I was frustrated at first because I thought I knew a lot about this topic, but from the other perspective. Being assigned to the opposite viewpoint made me really do my research and I learned a lot. I learned things that I didn't know were true ... it's changed my point of view." Another student wrote that she enjoyed the debate assignment because it helped her understand the debate topic: "Before, I did not understand [the debate topic]. However, this assignment made me change my mind and see that I agree with [the pro side of the argument] and because of this debate assignment, I now can articulate why to my clients and coworkers." Other students agreed and made comments like "I learned a lot" or "The debate was very informative." Several students commented specifically on skills they learned or further developed by working on the assignment. For example, one student said, "Though I have always enjoyed a good debate, I believe this assignment has helped to [improve] how to present an argument, listen to the other side, and refute [their arguments]." Likewise, another student wrote, "I learned so many skills during this debate, skills I will most definitely need to advocate for those people I serve." 
Improved critical thinking skills. A key benefit of debate in the literature is the development or improvement of critical thinking skills. This was reflected in students' comments: "Opening my mind to other opinions and letting go of my biases [was important]. It was then that I learned that I was able to see the problem or issue from both sides, rather than only my own." Another student wrote that this assignment "allowed me to see how people that I once thought were just insensitive could come to their conclusions. I learned that my point of view is not the only point of view out there." One student reflected on the varied skills gained from this project: "I have gained various insights from this assignment including critical thinking, researching and applying, adapting to group thinking, and most importantly, developing a perspective from a neutral, third-person context. Additionally, it made me realize that there is not always a right answer and this can relate to social policies in that they are subject to change as new information is researched, applied, and put forth through the persuasion process." Another student wrote, "Having to argue from a perspective that I did not agree with helped me become more objective and think critically." One student specifically applied her experience to those of policymakers: "I thought that we had thoroughly convincing evidence that our stance was correct, however, as I read the other point of view, I realized their stance was just as convincing. I can only imagine how difficult of a decision policymakers have in making decisions on social policy because every side can be argued exhaustively, extensively, and accurately based on current research. This assignment make me really think about how policy is created."

Enjoyed the assignment. Lastly, a common theme that emerged from the reflection papers was that students enjoyed the assignment. One student wrote, "Now that the debate is over, I must say that I am glad I did because it was very enjoyable .... I looked forward to the weekly challenges with this assignment." Another student wrote, "I learned and was challenged more than I expected with this project, thank you!" Several students wrote that the debate assignment was fun or engaging and they enjoyed collaborating with their peers.

\section{Discussion}

With online learning being a growing trend, educators will continue to grapple with adapting methods employed in face-to-face courses to an online mode of delivery (Bates \& Watson, 2008). This descriptive examination of online debate as an instructional method in a social policy course provides insight into a relatively new and unexplored way to engage students in online courses and enhance their learning and critical thinking skills. Based on survey data and qualitative data from reflection papers, students reported that the debate assignment was helpful in understanding course content, using or improving critical thinking skills, and with collaboration skills. Reflections on the process and recommendations are presented here in the hope that other faculty will replicate this assignment and examine their own experiences, and those of their students.

The survey data demonstrates that a majority of students felt the debate assignment helped them further understand course concepts, perhaps better than a lecture or reading would have. Some students addressed this in their reflection papers as well, noting that requiring them to engage with the scholarly literature to write their individual position statement before working with their group forced them to have at least a cursory understanding of the topic. While general information about the debate topic was provided, students were required to find their own scholarly support for their arguments. This active learning strategy puts students in charge of their own learning and 
allows them to learn and explore the topic on their own, as opposed to reading an assigned article or listening to a lecture. This is also consistent with Weeks' (2013) hypothesis that because online debates move more slowly than face-to-face, students have more time to reflect on their learning and compose more thoughtful arguments.

Both qualitative and quantitative data reflected that the assignment allowed students to use or improve critical thinking skills. Critical thinking skills are important in higher education and have been previously associated with student debate in a face-to-face classroom (Budesheim \& Lundquist, 1999; Kennedy, 2009; Omelicheva \& Avdeyeva, 2008; Schroeder \& Ebert, 1983). Critical thinking skills are also essential for effective policy practice (Gregory \& Holloway, 2005; Keller et al., 2001).

While not prominently reflected in the qualitative data, survey data indicated that the debate improved collaboration among students in the course. Requiring students to work together to create a group position and rebuttal statements helped improve their collaboration skills. Collaboration and communication were also required for students to successfully navigate group work in an online course. Fifty-seven percent of students agreed or strongly agreed that the debate experience had helped in other courses or work. This is an important statistic, given the nature of this course. Policy work requires being able to research, write, and collaborate with others in order to argue for or against a specific topic or issue. Students in this course were in the human services field and would likely need to advocate at some point for a client. Consistent with the limited previous work on debates in a traditional seated class on social policy (Gregory \& Holloway, 2005; Keller et al., 2001), the online debate appeared to provide the same benefits and skill development opportunities for students.

Only $28 \%$ of students reported that the debate project helped them feel more engaged in the course. This is surprising, given the number of qualitative comments about the positive outcomes of group work. It is possible that students felt more connected to their group members but not necessarily the course as a whole. It is also possible that the debate project took their focus away from other course assignment and objectives, leaving students feeling engaged in the debate but disengaged from the course itself.

\section{Limitations and Directions for Future Research}

While this study provides insight into this assignment and its outcomes and lends credibility to the use of online debate in an asynchronous course, there are limitations. First, this is a small sample with a very specific assignment. It is unknown, for example, whether an assignment with this level of detail and number of components could be as effectively deployed in a larger class in order to increase sample size. Another limitation is that the professor of the course developed the assignment, analyzed the data, and wrote this paper. While objectivity was prioritized, there is likely some bias present, or perhaps students did not share as much as they might have with a third party. While the data presented here is very positive overall, there were likely problems or complaints that students did not share. Further exploration, perhaps through individual interviews with students or groups, would likely shed light on some of these issues. Additionally, while this study presents student satisfaction and perceptions of learning, actual student learning was not measured, nor were any pretests or baseline assessments given. Future research may want to assess students' critical thinking skills before, during, and after such an assignment. Likewise, levels of student engagement and/or collaboration could also be assessed. 


\section{Implications and Recommendations for the Classroom}

Based on the experience of developing, implementing, and examining a debate assignment in an online asynchronous course and the themes from students' qualitative feedback, the following recommendations are offered to other faculty considering a similar assignment. Given the students' apprehension and wariness about the assignment from the beginning, it is recommended that faculty incorporate a team-building exercise into the beginning of the course to provide more time for students to get to know one another and to feel more confident in collaborating on the project. The importance of providing clear, detailed instructions cannot be overstated. In their study of online debate as an instructional tool, Hodgkinson-Williams and Mostert (2005) reported that one potential obstacle reported by students was that the goal and procedures of the debate needed to be clear from the outset. Mutiaraningrum and Cahyono (2015) also noted the importance of clear guidelines and steps required to participate in an online debate. Thus, the assignment guidelines for this project are detailed and rather long. Students reported that having a detailed guide was helpful, however, especially in an online class where you do not see the students face-to-face to present the project and answer questions. This is no different, however, than the clarity needed in all assignments in online courses.

Having viewpoints and opinions challenged was also a common theme in student feedback. Assigning students to a pro or con perspective forces them to think more objectively and research the facts, not just rely on their opinions. One student even suggested that groups be assigned based on students' individual position statement; once students submit their position, assign them to the opposing viewpoint to argue. Indeed, Hodgkinson-Williams and Mostert (2005) found that students learned more by having to argue an assigned point of view, often conflicting with their own. Giving students time to process this assigned position and the slower nature of an asynchronous debate (compared to a traditional debate) proved helpful, allowing more time for contemplation and thoughtful response. This is consistent with previous literature (HodgkinsonWilliams \& Mostert, 2005; Mutiaraningrum \& Cahyono, 2015; Weeks, 2013).

Group conflict and communication was another key theme. When the course is online and asynchronous, students may need support and suggestions for connecting with their peers. As one student suggested, using Skype or another videoconferencing platform may be helpful. Providing structured group space on the course learning management system or suggesting platforms such as Google Drive might be an opportunity to help bring groups together and promote collaborative work. Also, as noted above, providing a team-building exercise or an opportunity to connect as a group may be helpful in alleviating these concerns. Once students engage in the process, most enjoy the debate and report learning relevant information and skills. It is important to assure students this is a manageable project and to provide support and consultation as necessary.

Gaining knowledge and critical thinking skills were themes from the student data and are reflected in prior literature as well. As noted, having student write their own position statement before working with their group gives them a starting point. Doing their own research requires them to learn about the topic and their assigned perspective. Having students work with others to create a group statement forces them to evaluate what information from their individual papers to include and how to collaborate with others. Creating a group rebuttal statement requires students to read and analyze the other side's argument and craft a thoughtful response (Zare \& Othman, 2015). The structure of this assignment allows multiple opportunities for students to learn and develop knowledge and skills. 


\section{Conclusion}

With online learning being a growing trend, educators will continue to grapple with adapting methods employed in face-to-face courses to an online mode of delivery and with developing new approaches and methods of instruction. This descriptive examination of debate as an instructional method in an online asynchronous policy course provides insight into a relatively unexplored way to engage students in online courses and enhance their learning and critical thinking skills. The data presented here support the success of this assignment. It is hoped that this case study will provide lessons learned so that more online instructors might use asynchronous debates in their teaching and examine the effectiveness and impact of the tool for themselves. 


\section{References}

Bates, C., \& Watson, M. (2008) Re-learning teaching techniques to be effective in hybrid and online courses. Journal of American Academy of Business, 13(1), 38-44.

Budesheim, T. L., \& Lundquist, A. R. (1999). Consider the opposite: Opening minds through inclass debates on course-related controversies. Teaching of Psychology, 26(2), 106-110. https://doi.org/10.1207/s15328023top2602_5

Clark, R. E. (1994). Media and method. Educational Technology Research and Development, 42(3), 7-10. https://doi.org/10.1007/BF02298090

Freeley, A. J. (1996). Argumentation and debate: Critical thinking for reasoned decision making (9th ed.). Belmont, CA: Wadsworth.

Garrison, D. R., Anderson, T., \& Archer, W. (2001). Critical thinking, cognitive presence, and computer conferencing in distance education. American Journal of Distance Education, 15(1), 3-21. https://doi.org/10.1080/08923640109527071

Gregory, M., \& Holloway, M. (2005). The debate as a pedagogic tool in social policy for social work students. Social Work Education, 24(6), 617-637. https://doi.org/10.1080/02615470500182132

Hamzaee, R. A. (2005). A survey and theoretical model of distance education programs. International Advances in Economic Research, 11(2), 215-229. https://doi.org/10.1007/s11294-005-3017-6

Hodgkinson-Williams, C., \& Mostert, M. (2005). Online debating to encourage student participation in online learning environments: A qualitative case study at a South African University. International Journal of Education and Development using ICT, 1(2), 94104. Retrieved from https://www.learntechlib.org/p/42227/

Keller, T. E., Whittaker, J. K., \& Burke, T. K. (2001). Student debates in policy courses: Promoting policy practice skills and knowledge through active learning. Journal of Social Work Education, 37(2), 343-355. https://doi.org/10.1080/10437797.2001.10779059

Kennedy, R. R. (2009). The power of in-class debates. Active Learning in Higher Education, 10(3), 225-236. https://doi.org/10.1177/1469787409343186

Mutiaraningrum, I., \& Cahyono, B. Y. (2015). Online debate in argumentative writing course: Potentials and challenges. International Journal of Language and Linguistics, 2(4), 4354.

Omelicheva, M. Y., \& Avdeyeva, O. (2008). Teaching with lecture or debate? Testing the effectiveness of traditional versus active learning methods of instruction. Political Science and Politics, 41, 603-607. https://doi.org/10.1017/S1049096508080815

Park, C., Kier, C., \& Jugdev, K. (2011). Debate as a teaching strategy in online education: A case study. Canadian Journal of Learning and Technology, 37(3), 1-17. https://doi.org/10.21432/T2FW2R

Richardson, J. C., \& Ice, P. (2010). Investigating students' level of critical thinking across instructional strategies in online discussions. Internet and Higher Education, 12(2), 5259. https://doi.org/10.1016/j.iheduc.2009.10.009 
Schroeder, H., \& Ebert, D. G. (1983). Debates as a business and society teaching technique. Journal of Business Education, 58(7), 266-269. https://doi.org/10.1080/00219444.1983.10534907

Seaman, J. E., Allen, I. E., \& Seaman, J. (2018). Grade increase: Tracking distance education in the United States. Babson Survey Research Group. Retrieved from https://onlinelearningsurvey.com/reports/gradeincrease.pdf

Weeks, P. P. (2013). Examining online debate and discussion. Academic Exchange Quarterly, 17(1), 55-59. http://rapidintellect.com/AEQweb/5204new.pdf

Zare, P., \& Othman, M. (2015). Students' perceptions toward using classroom debate to develop critical thinking and oral communication ability. Asian Social Science, 11(8), 158-170. https://doi.org/10.5539/ass.v11n9p158 